\title{
INTERNATIONAL SUMMER STUDENT SEMINAR (3S), FROM IDEA TO REALIZATION
}

\author{
A.P. Karpik ${ }^{a}$, A. Peled ${ }^{b}$, I.A. Musikhin ${ }^{a}$, Li Deren $^{c}$, V.A. Seredovich ${ }^{a}$ \\ ${ }^{a}$ Siberian State Academy of Geodesy, 10 Plakhotnogo Str., Novosibirsk, 630108, Russia - \\ rector@ssga.ru, igor_musihin@mail.ru,v.seredovich@list.ru \\ ${ }^{\mathrm{b}}$ University of Haifa, Dept. of Geography and Environmental Studies Haifa,31905, Israel - \\ peled@geo.haifa.ac.il \\ ${ }^{c}$ Wuhan University, the State Key Laboratory for Information Engineering in Surveying, Mapping and \\ Remote Sensing, No129 Luo Yu Road, Wuhan, China, 430079 - dli@ wtusm.edu.cn
}

\section{Commission VI, WG VI/4}

KEY WORDS: 3S, cooperation, SSGA, Wuhan University, MIIGAiK, ISPRS

\begin{abstract}
:
The article gives a spotlight on a three universities (Moscow State University of Geodesy and Cartography, Siberian State Academy of Geodesy, Wuhan University) and ISPRS' cooperation in organizing and holding summer student seminars for undergraduate, master, and PhD students of the universities specializing in photogrammetry, remote sensing, GIS, aerial and space cartography. Principles of topics of the seminar selection, lecture courses delivering and practical training as well as international joint team work on projects and their defence are described. The description of the basic stages of $3 \mathrm{~S}$ implementation, and the goals of this sort of the international event is given.
\end{abstract}

\section{INTRODUCTION}

In 2009 at the International Scientific Congress and Exhibition "GEO-Siberia", Novosibirsk, Russia, through intermediary and encouragement of ISPRS, a Memorandum of Understanding for Academic and Scientific Cooperation was signed among Moscow State University of Geodesy and Cartography (MIIGAiK), Siberian State Academy of Geodesy (SSGA), and Wuhan University (WU) - three major institutions of higher education in the fields of Photogrammetry, Remote Sensing, Geodesy and Cartography. It was ISPRS that proposed to operate a summer seminar where recognized experts would address students of the three universities on issues related to spatial sciences, which would allow the young generation of different countries to be aware of up-to-date trends in the field of spatial sciences as well as to establish scientific contacts with those who are to become a leading hand in their countries in 1015 years

\section{SUMMER STUDENT SEMINAR - 2010}

It was agreed to hold the student seminars every year starting with the first 3S-2010 at the SSGA, Novosibirsk 21-25 September 2010. By the terms of the Memorandum a host university provides accommodation, meals, and cultural programme of the participants on its own expense, it also defrays transport charges of all invited ISPRS experts.

The 3S-2010 organisation routines were divided into several stages:

- topics of the 3S (the three universities, ISPRS);

- expert selection (ISPRS);

- looking for funding sources (SSGA);

- advertising campaign: mailing, development of the event website (SSGA, ISPRS);

- technical issues (SSGA).
At the first and second stages ISPRS, thanks to its second vicepresident Prof. Peled, found matching topics of interest among all the three universities, which allowed ISPRS to start searching for proper experts. The described above activities had taken approximately 4 months following which four courses were chosen:

- Geo-information for Disaster Management, Prof. Zlatanova, Netherlands;

- Geomatics supporting Disaster Management, Prof. Tolono, Prof. Ajmar, Italy;

- GIS-Driven RS-Based Automatic Updating of Spatial Data bases, Prof. Peled, Israel;

- Human - centric approach in geospatial technology for emergency situation response, Prof. Levin, USA.

To estimate the average amount of money needed for the event the SSGA appraised of all of the items of expense. When the total sum was determined it was clear that the Academy would need to look for some additional funding sources. As a result of undertaking activities the SSGA managed to get a regional grant and hold 3S-2010 as an event within International Youth Forum INTERRA-2010.

At the fourth stage the SSGA mailed letters of information to all of the interested parties and developed the website of the 3S2010, where general information about the event, its lectures and short description of the seminar courses were published. The advertising campaign attracted to the 3S-2010 some more participants from Israel (Haifa University), Kazakhstan (Eastern Kazakhstan State Technical University), USA (Michigan Technological University), and Nigeria. As for technical issues, here the questions of accommodation, transportation, meals, materials of the student conference publishing, cultural activities and courses schedule were solved. 


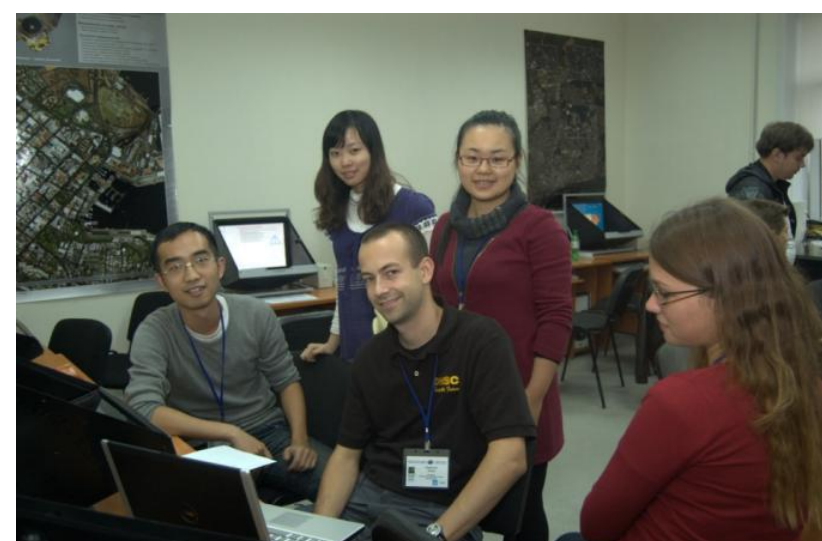

Figure 1. Practical studies in a lab

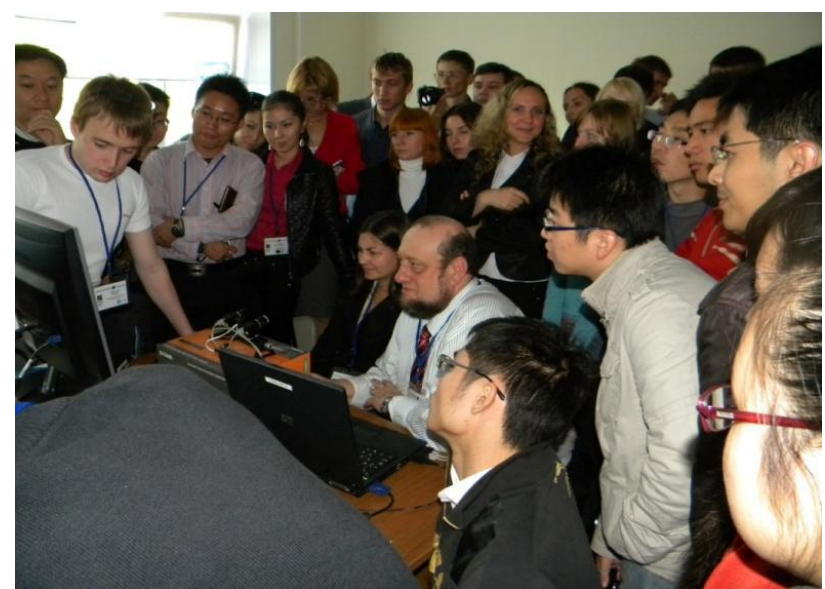

Figure 2. Master class by Prof. Levin

The 3S-2010 embodied four major courses and practicals that lasted for four days, figures 1,2,4. Several courses implied team research and project work which was defended in front of all participants and experts, figure 3 .

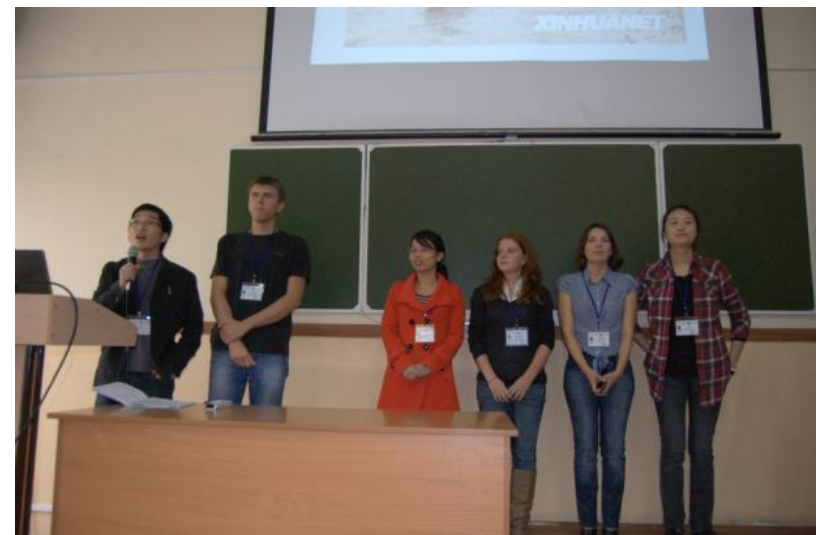

Figure 3. Defending a project

For this purpose all of the students were divided into international groups so that they would be able to take into consideration the experience of different schools of education when working on the projects.

The 3S-2010 courses and practicals started at 9.00 a.m. and finished at 16.30 then the students and experts were offered to participate in the cultural programme. After the courses of the event the students were asked to analyze the advantages and disadvantages of the $3 \mathrm{~S}$ and also give the organizers their ideas on the 3S-2011 in Wuhan. The last day of the seminar a special conference was organized by the SSGA undergraduates and $\mathrm{PhD}$ students where the main results of their research activities were presented after which the floor was given to the international teams to share their ideas for 3S-2011.

\section{SUMMER STUDENT SEMINAR - 2011}

The 3S-2011 at Wuhan University was organized with taking into account most of the event conditions proposed at 3S-2010 that allowed to have a much better success.

The 3S-2011 organisation activities included the following stages:

- topics of the 3S (the three universities, ISPRS);

- expert selection (ISPRS);

- looking for funding sources (WU);

- advertising campaign: mailing, development of the event website (WU, SSGA, ISPRS);

- technical issues (WU, SSGA).

At 3S-2011 there were two main courses devoted to LIDAR and RADAR applications, delivered by experts from Germany, Austria and Italy (Figure 4).

In 3S-2011 participated students from one more university Mongolian State University of Technology.

After the event the host university organized a very well organized and considered cultural programme that allowed the participants to know and understand history and traditions of China at a new level that undoubtfully led to a better cooperation among students.

\section{SUMMER STUDENT SEMINAR - 2012}

The 3S-2011 organizers, representatives of ISPRS and SSGA discussed the main trends of 3S-2012 that would be held in Moscow. It was agreed that ISPRS and the partner universities would do their best to attract sponsors to support $3 \mathrm{~S}$ events in 2012-2014 (Figure 5).

It was agreed that in 2012 a new Memorandum of Academic and Scientific cooperation would be signed in Moscow allowing other universities to join the $3 \mathrm{~S}$ activities as part-time participants and at the level of full members. At 3S-2012 the questions of member fee as well as participation fees will be brought up. The subjects for the discussion of the working meetings at 3S-2012 will also be:

- The $3 \mathrm{~S}$ programme will emphasize the cooperation with others and should promote the spirit of comradeship.

- First 3S-2013 will be launched by SSGA, Novosibirsk, 2125 September 2013.

- Host Universities will provide free accommodation, meals, and participation to students from the full member universities. Other may be subjected to a fee.

- Participation of students from other full member universities will be limited by minimum and maximum thresholds.

- The topic of the Seminars will be decided beforehand by agreement of the parties.

- The lectures of the $3 \mathrm{~S}$ should both from abroad and the hosting university.

- Cultural aspects should be mandatory in the programme as well.

- It would be wise to have ISPRS Workshop in Novosibirsk 


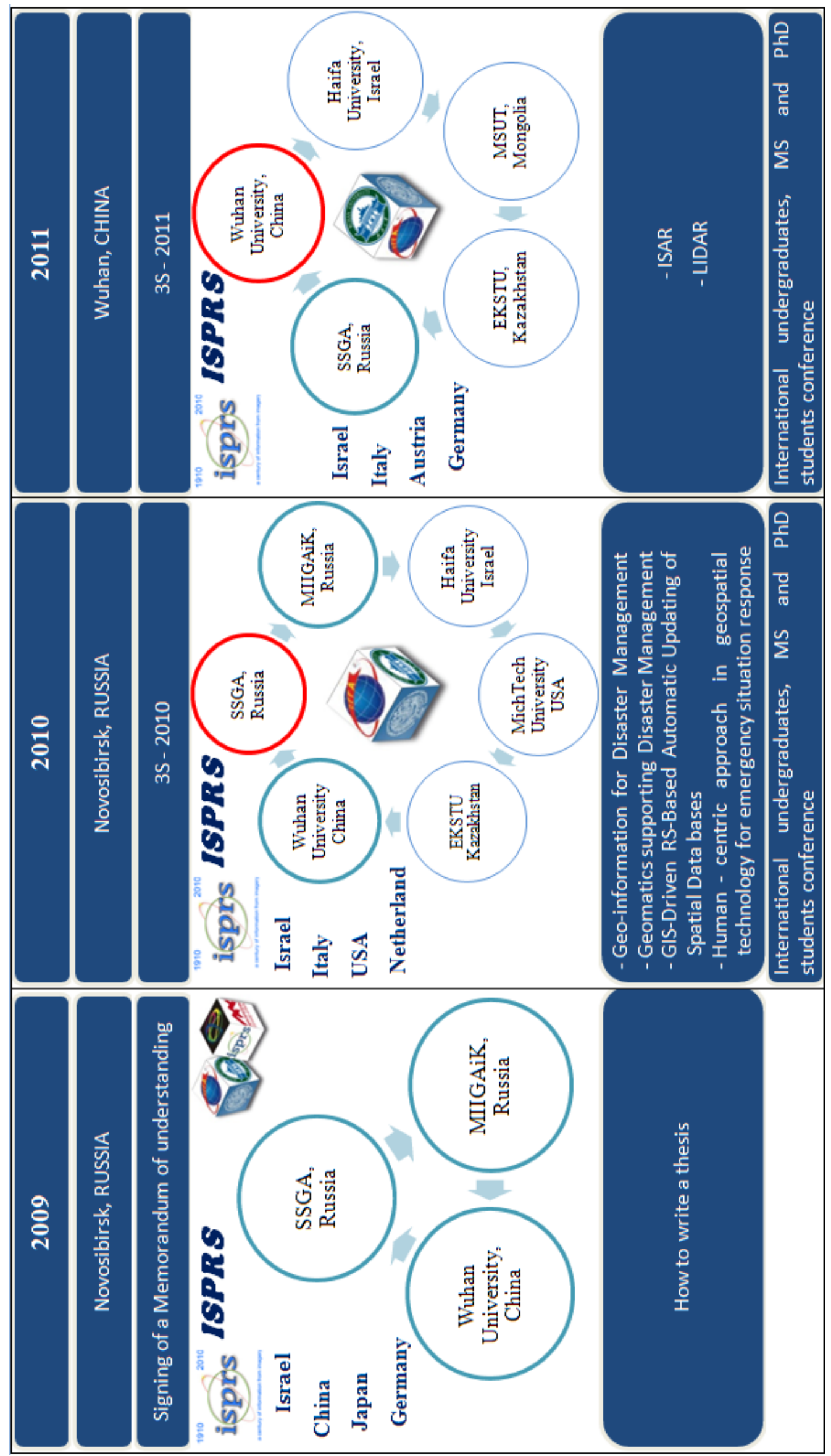

Figure 3. 3S historiography (2009-2011) 

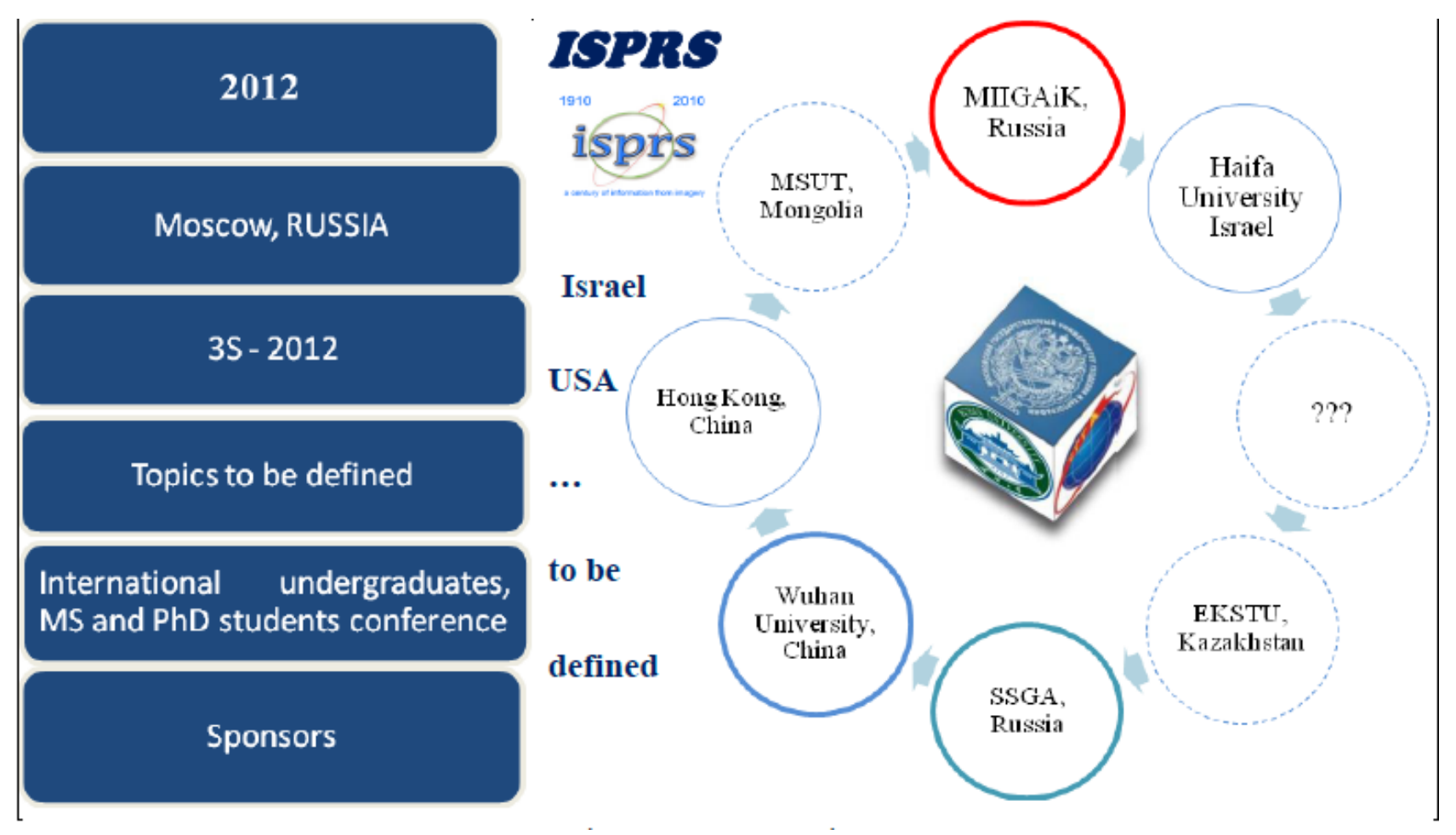

Figure 5. 3S - 2012 in Moscow

in 2013, parallel to the 3S-2013 so it would be possible to attract more potential presenters.

- The 3S should aim at all levels of students, undergraduate, graduate, $\mathrm{PhDs}$, etc.

- Each full member university, including ISPRS, will have a point of contact for the $3 \mathrm{~S}$.

\section{CONCLUSIONS}

The experience of 3S 2010-2011 makes us sure that the format of the event can be regarded as a rather successful form of scientific and academic cooperation both among universities and students and can be considered as a "bridge" between generations. In future such activities may develop into a closer research cooperation and participation in joint scientific and academic projects which will result to common benefit of all participants of the event. 